\title{
Pathogenesis of Chiari malformation: a morphometric study of the posterior cranial fossa
}

\author{
Misao Nishikawa, M.D., Hiroaki Sakamoto, M.D., Akira Hakuba, M.D., Naruhiko Nakanishi, \\ M.D., and Yuichi Inoue, M.D.
}

Departments of Neurosurgery and Radiology, Osaka City University Medical School, Osaka, Japan

To investigate overcrowding in the posterior cranial fossa as the pathogenesis of adult-type Chiari malformation, the authors studied the morphology of the brainstem and cerebellum within the posterior cranial fossa (neural structures consisting of the midbrain, pons, cerebellum, and medulla oblongata) as well as the base of the skull while taking into consideration their embryological development. Thirty patients with Chiari malformation and 50 normal control subjects were prospectively studied using neuroimaging. To estimate overcrowding, the authors used a "volume ratio" in which volume of the posterior fossa brain (consisting of the midbrain, pons, cerebellum, and medulla oblongata within the posterior cranial fossa) was placed in a ratio with the volume of the posterior fossa cranium encircled by bony and tentorial structures. Compared to the control group, in the Chiari group there was a significantly larger volume ratio, the two occipital enchondral parts (the exocciput and supraocciput) were significantly smaller, and the tentorium was pronouncedly steeper. There was no significant difference in the posterior fossa brain volume or in the axial lengths of the hindbrain (the brainstem and cerebellum). In six patients with basilar invagination the medulla oblongata was herniated, all three occipital enchondral parts (the basiocciput, exocciput, and supraocciput) were significantly smaller than in the control group, and the volume ratio was significantly larger than that in the Chiari group without basilar invagination.

These results suggest that in adult-type Chiari malformation an underdeveloped occipital bone, possibly due to underdevelopment of the occipital somite originating from the paraxial mesoderm, induces overcrowding in the posterior cranial fossa, which contains the normally developed hindbrain. Basilar invagination is associated with a more severe downward herniation of the hindbrain due to the more severely underdeveloped occipital enchondrium, which further exacerbates overcrowding of the posterior cranial fossa.

Key Words * skull base * basilar invagination * Chiari malformation * occipital bone * posterior cranial fossa $*$ syringomyelia

Chiari malformation is characterized by a downward herniation of the caudal part of the cerebellum and/or medulla oblongata into the spinal canal. This malformation is classified into at least two distinct types according to the degree of herniation: Type I displays herniation of the cerebellar tonsils and Type II exhibits herniation of the fourth ventricle and the medulla oblongata as well as the caudal part of the 
cerebellum.[5] From a clinical point of view, Chiari malformation can also be divided into adult and pediatric types.[9] The adult-type Chiari malformation falls mostly into Type I and usually presents after the second or third decade of life with symptoms and signs resulting from tightness of the posterior cranial fossa and/or from associated syringomyelia.[3,4,8,14,21] This type is often accompanied by bone anomalies in the base of the skull such as basilar invagination, but is less frequently associated with brain abnormalities other than herniation of the cerebellar tonsils. The pediatric type mainly belongs to Chiari Type II and is characterized by myeloschisis at birth and brainstem dysfunction in the early periods after birth.[2,5,8,21] Typical features include a small posterior cranial fossa and various neural abnormalities such as brainstem deformities and hydrocephalus.[2,3,5,21]

Chiari malformation is considered to be a primary neurological disease involving the posterior cranial fossa and the hindbrain.[2] Many investigators have tried to explain the pathogenesis of Chiari malformation from the standpoint of primary neural anomaly.[2,10,18] However, clinical and experimental studies indicate that the chronic tonsillar herniation observed in Chiari malformation could result from overcrowding within a primary small and shallow posterior cranial fossa due to an underdeveloped occipital bone. $[9,16,17]$ Recent morphometric studies focusing on the bony part of the posterior cranial fossa in adult patients with Chiari malformation have lent support to this hypothesis.[23,25,28]

In the present study, to estimate properly the overcrowding of the posterior cranial fossa in adult-type Chiari malformation without myelodysplasia, we quantitatively measured the volume of the whole posterior cranial fossa encompassed by both the bony and tentorial parts as well as the volume of the neural structures (the brainstem and cerebellum) within the posterior cranial fossa. The results obtained strongly suggest that overcrowding in the posterior cranial fossa due to an anomaly in the embryological development of the base of the skull is the pathogenesis of Chiari malformation.

\section{CLINICAL MATERIAL AND METHODS}

Patients with adult-type Chiari malformation (the Chiari group) who were selected for this prospective study were strictly chosen through surgical exploration of the major cistern in addition to neuroimaging. Of 58 patients with hindbrain herniation (without myelodysplasia) surgically treated at our hospitals, eight with basal meningitis or hydrocephalus were excluded. Another 20 patients who were diagnosed as having adult-type Chiari malformation before the era of magnetic resonance (MR) imaging were also excluded. The remaining 30 patients consecutively diagnosed as having adult-type Chiari malformation between June 1987 and June 1995 at Osaka City University Medical School and Osaka City General Hospital were investigated. Twenty-six of these patients displayed symptomatic syringomyelia and four presented with neurological signs caused by impairment of the cerebellum, medulla oblongata, or both due to a tight posterior cranial fossa. Of these 30 patients, 22 displayed no herniation of the medulla oblongata. The remaining eight showed mild herniation of the medulla oblongata below the foramen magnum in addition to tonsillar herniation; two had a downward herniation of the fourth ventricle with cervicomedullary kinking visible on the MR image, six had basilar invagination, one had assimilation of the atlas, and one had Klippel-Feil syndrome.[24] All patients with basilar invagination manifested medullary herniation. As a control group we studied 50 normal individuals without central nervous system involvement between June 1987 and June 1995 at Osaka City University Medical School and Osaka City General Hospital. Table 1 provides a summary of the subjects of each radiological study. 


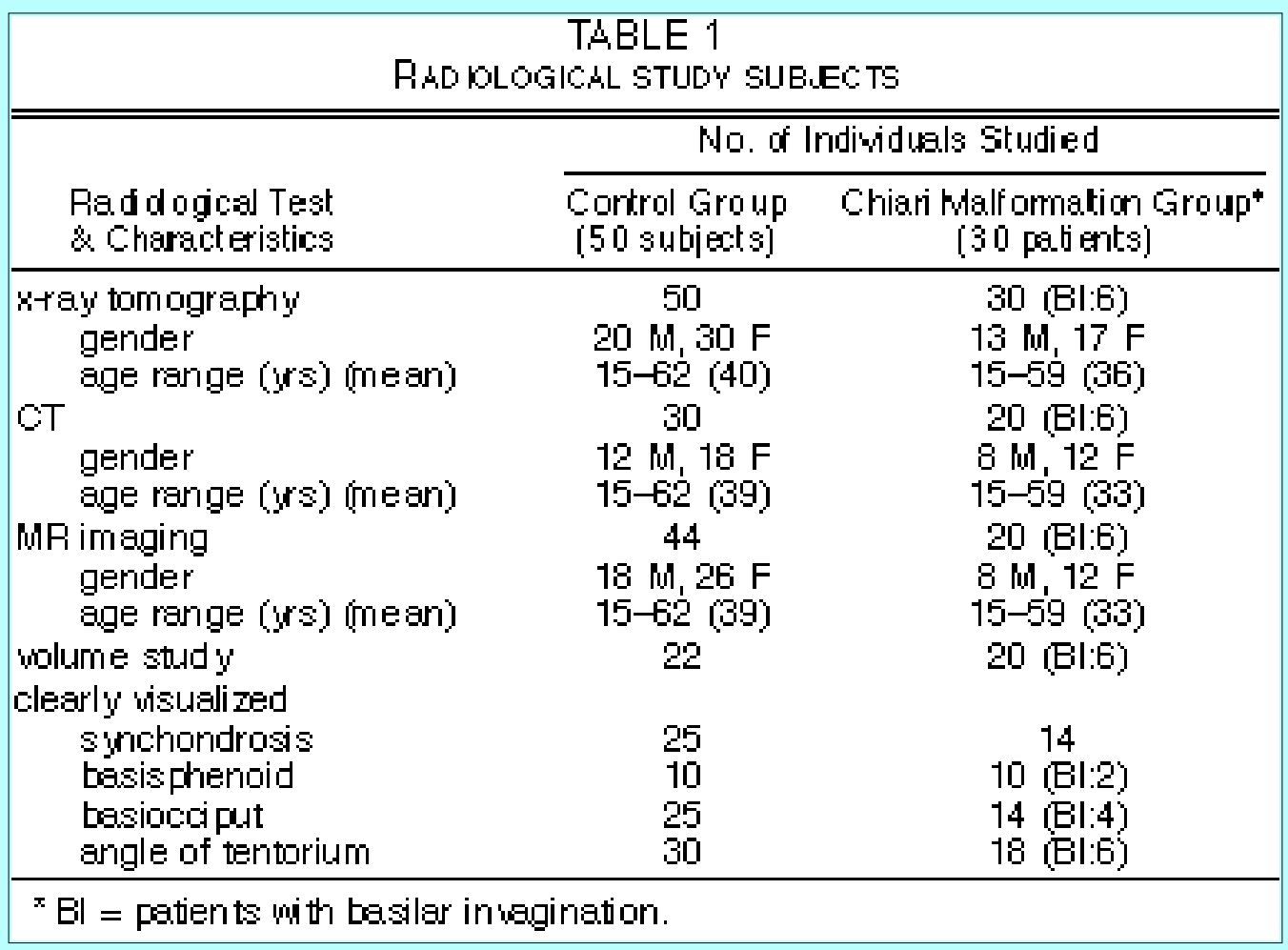

\section{Quantitative Measurement by X-Ray Tomography}

An attempt was made to measure accurately the three occipital enchondral parts: the supraocciput, exocciput, and basiocciput. The axial length of the clivus (the basiocciput and basisphenoid) was measured from the top of the dorsum sellae to the basion (Fig. 1 upper). The length of the supraocciput was defined as the distance between the internal occipital protuberance and the opisthion measured on midline films (Fig. 1 upper). The length of the exocciput was measured from the bottom of the occipital condyle to the top of the jugular tubercle at the level of the hypoglossal canal in anteroposterior view films vertical to the orbitomeatal line (Fig.1 center).

Tomograms of the basicranium were obtained (Polytome U tomographical system; Philips, Einthourr, Holland), and measurements were recorded for all 30 patients and 50 control subjects.

Fig. 1. X-ray tomography and magnetic resonance (MR) imaging measurements. Upper: $\mathrm{X}$-ray tomogram (lateral midline view) showing the length of the clivus and the length between the internal occipital protuberance and the opisthion. Center: X-ray tomogram (anteroposterior view) showing the jugular tubercle and the occipital condyle with the hypoglossal canal. The straight line demonstrates the length of the exocciput between the bottom of the occipital condyle and the top of the jugular tubercle. At = lateral mass of the atlas; $\mathrm{D}=$ dens of the axis; H.C. = hypoglossal canal; J.T. = jugular tubercle; O.C. = occipital condyle. 


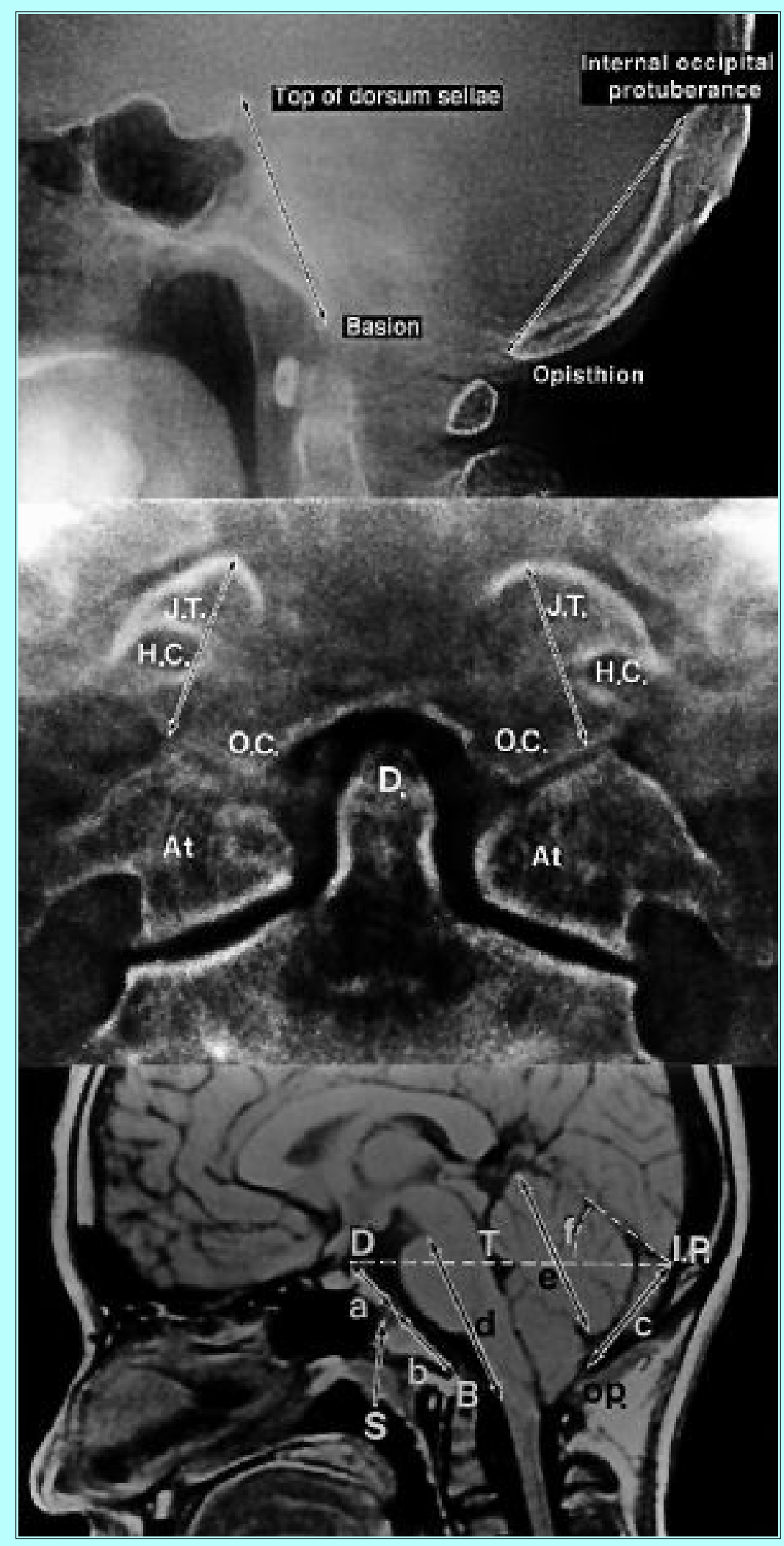

Lower: A T1-weighted sagittal MR image showing the midline structures of the posterior cranial fossa and the brainstem and cerebellum. $\mathrm{a}=$ length of the basisphenoid between the top of the dorsum sellae and the sphenooccipital synchondrosis of the clivus; $b=$ length of the basiocciput between the synchondrosis and the basion; $c=$ length of the supraocciput between the internal occipital protuberance and the opisthion; $d=$ length of the hindbrain (brainstem) between the midbrain-pons junction and the medullocervical junction; $\mathrm{e}=$ length of the hindbrain (cerebellar hemisphere); $\mathrm{f}=$ angle of the cerebellar tentorium to Twining's line. $\mathrm{B}=$ basion; $\mathrm{D}=$ top of the dorsum sellae; I.P. = internal occipital 
protuberance; O.P. = opisthion; $\mathrm{S}=$ sphenooccipital synchondrosis of the clivus; $\mathrm{T}=$ Twining's line.

\section{Volume Study by Computerized Tomography}

We defined the total volume of the posterior cranial fossa (PFCV: posterior fossa cranial volume) as the space encircled by the tentorium of the cerebellum, clivus, occipital bone, and pyramidal bone. Axial images were obtained using computerized tomography (CT) (Somatom; Siemens, Erlangen, Germany) after intravenous administration of contrast medium.

The images were made with a reference line drawn between the basion and opisthion, corresponding to the horizontal plain of the foramen magnum, on the lateral scout view of the CT scan. The sigmoid sinus was arbitrarily included as part of the posterior cranial fossa but the jugular foramen was not. The petroclinoid ligament was regarded as the external margin and the tentorial hiatus as the most cephalic margin of the posterior cranial fossa. The slice width was 0.3 to $0.8 \mathrm{~cm}$ and the window level was set at $250 / 30$ to $1000 / 30$. The area calculated was multiplied by the slice width to obtain the volume. Computerized tomography scanning was used to study the PFCV in the 20 most recent patients and in 30 normal subjects.

\section{Morphometric and Volume Studies of the Contents Within the Posterior Cranial Fossa by MR Imaging}

The structures of the brain and base of the skull were investigated using MR imaging (Signa 1.5-tesla; General Electric, Milwaukee, WI) (Fig. 1 lower). The T1-weighted images were obtained using a repetition time of 500 to $600 \mathrm{msec}$ and an echo time of 15 to $40 \mathrm{msec}$; the T2-weighted images were obtained using a repetition time of 3000 to $4000 \mathrm{msec}$ and an echo time of 80 to $100 \mathrm{msec}$. Axial and sagittal images were obtained at 3- to 5-mm intervals.

The clivus was divided into two parts, basisphenoid and basiocciput, with the basioccipital synchondrosis as the demarcation. Using midline sagittal MR imaging, we measured the length from the synchondrosis to the top of the dorsum sellae as constituting the basisphenoidal part of the clivus, and the length from the synchondrosis to the basion as the basioccipital portion. To determine the axial length of the brainstem (pons and medulla oblongata), the distance between the ventral point of the midbrain-pons junction and the medullocervical junction was measured on both T1- and T2-weighted images.[13] The medullocervical junction was defined as the level at which the pyramidal tract changed its route on the T2-weighted image.[13] The long axial length of the cerebellar hemisphere was measured on T1-weighted sagittal images from the highest to the lowest point of the cerebellar hemisphere along a straight line drawn caudally and parallel to the bottom of the fourth ventricle. To estimate the steepness of the cerebellar tentorium, the angle of the cerebellar tentorium to Twining's line was measured on sagittal images.

The volume of the brainstem and cerebellum within the posterior cranial fossa (PFBV: posterior fossa brain volume) was measured using MR imaging. The PFBV was defined as the volume of the neural structures contained within the posterior cranial fossa as measured on CT scans, including the parts of the brain that herniate into the spinal canal. The total PFBV thus consisted of the midbrain, pons, cerebellum, and medulla oblongata. This PFBV was measured on T1-weighted axial images, and the volume ratio of the PFBV to the PFCV was then calculated on the basis of results of CT and MR imaging by a volume study to estimate overcrowding of the posterior cranial fossa. 
Statistical Analysis

The values of all parameters measured for the Chiari group and the control group were comparatively assessed using the Mann-Whitney test. The volume data, volume ratio, and angle of the tentorium were compared using the linear regression test.

\section{RESULTS}

\section{Quantitative Measurement by X-Ray Tomography}

Although the mean length of the clivus in the Chiari group was not significantly shorter than that in the control group (49.7 $\mathrm{mm}$ in the Chiari group and $50.1 \mathrm{~mm}$ in the control group), it was significantly ( $<$ $0.01)$ shorter $(39.8 \mathrm{~mm})$ in the six patients with basilar invagination of the eight patients displaying downward herniation of the medulla oblongata (Fig. 2 upper left).

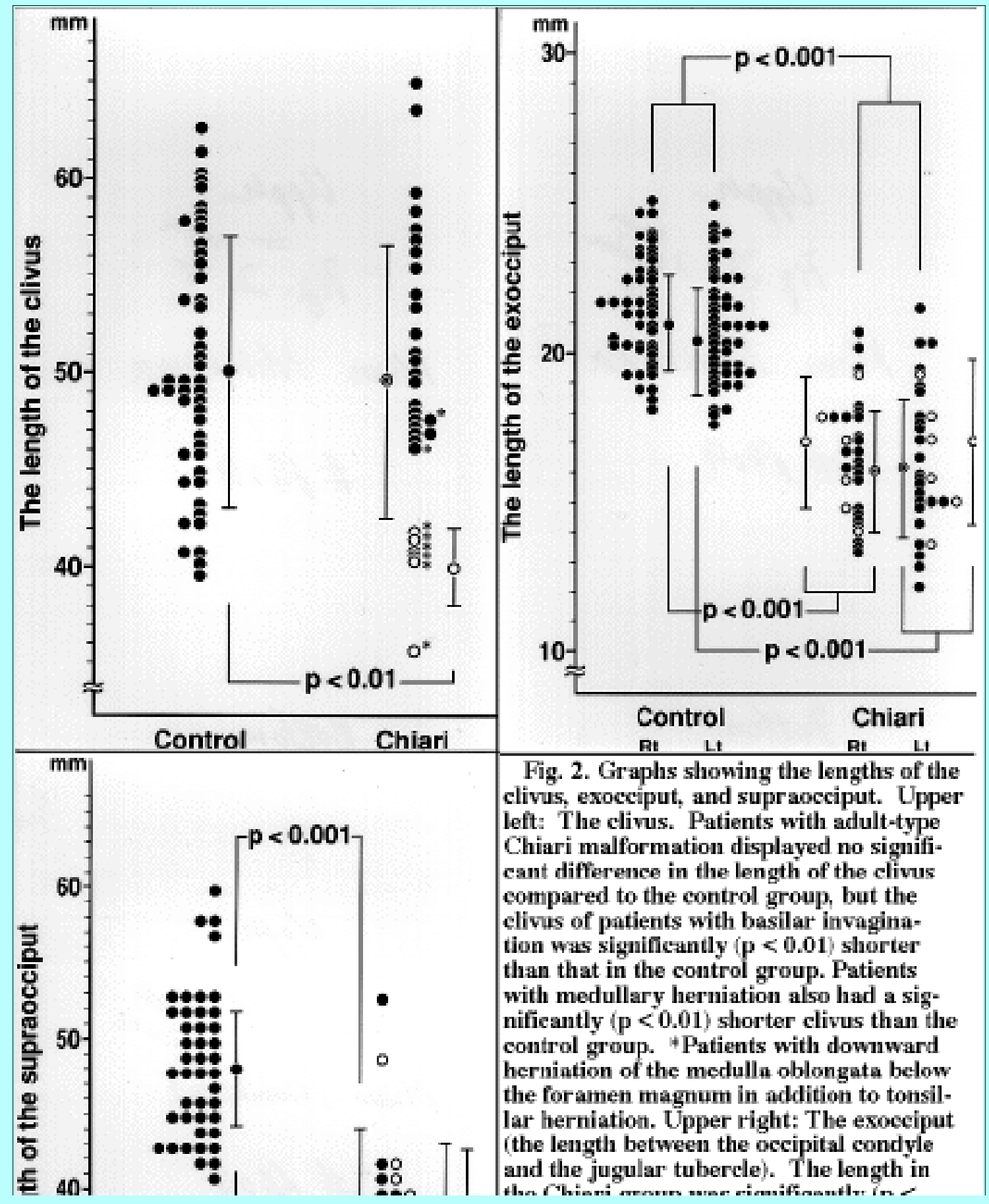




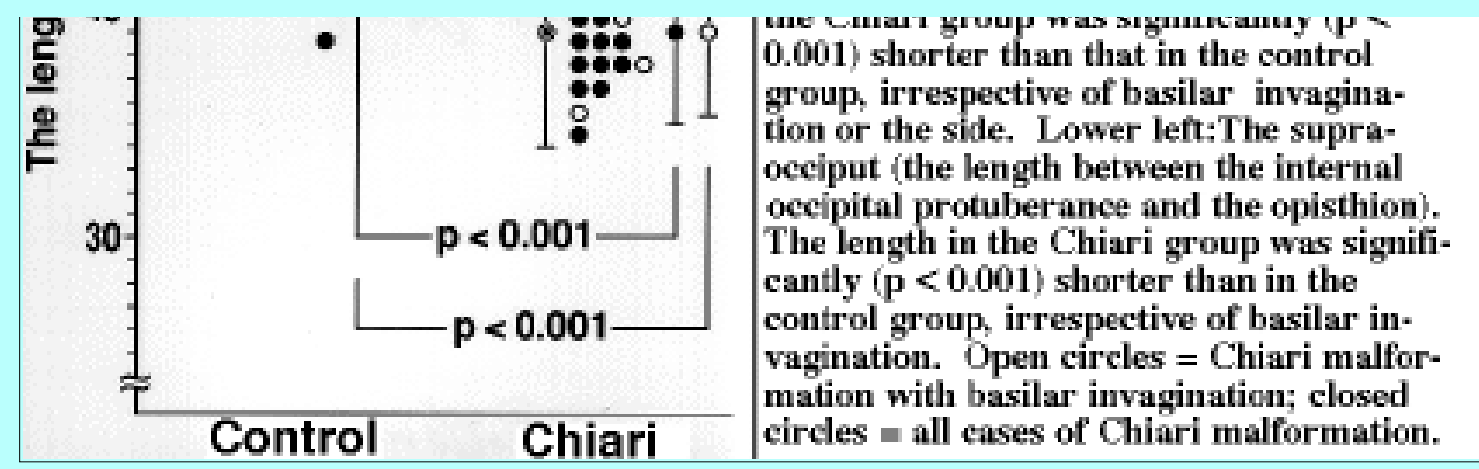

A significant difference $(\mathrm{p}<0.001)$ was found in the mean length of the exocciput from the bottom of the occipital condyle to the top of the jugular tubercle, which measured $16 \mathrm{~mm}$ (16 $\mathrm{mm}$ on the right side and $16.1 \mathrm{~mm}$ on the left side) in the Chiari group and $20.5 \mathrm{~mm}(20.9 \mathrm{~mm}$ on the right side and $20.2 \mathrm{~mm}$ on the left side) in the control group. It was significantly $(\mathrm{p}<0.001)$ shorter irrespective of the side. It was also significantly $(\mathrm{p}<0.001)$ shorter in patients with basilar invagination $(16.8 \mathrm{~mm}$ on the right side and $16.7 \mathrm{~mm}$ on the left side) (Fig. 2 upper right).

A significant difference $(\mathrm{p}<0.001)$ was also found in the mean length of the supraocciput between the internal occipital protuberance and the opisthion, which measured $38.9 \mathrm{~mm}$ in the Chiari group and 48.1 $\mathrm{mm}$ in the control group. It was also significantly $(\mathrm{p}<0.001)$ shorter in patients with basilar invagination $(38.9 \mathrm{~mm})$ (Fig. 2 lower left).

\section{Volume Study by CT and MR Imaging}

There was no significant difference between the Chiari group and the control group in the mean PFCV as measured by CT scanning, which was 186 cubic centimeters in the Chiari group (188 cubic centimeters in patients without vs. 184 cubic centimeters in those with basilar invagination) and 193 cubic centimeters in the control group (Fig. 3 upper left). No significant difference was found in the PFBV, which was 156 cubic centimeters in the Chiari group (156 cubic centimeters in patients without vs. 157 cubic centimeters in those with basilar invagination) and 153 cubic centimeters in the control group (Fig. 3 upper right). Because the exact location of Twining's line as the border of the bony and tentorial portions of the posterior cranial fossa could not be accurately observed on the axial MR images, the PFBV encompassed by each of the bony and tentorial parts could not be separately calculated. The overall results showed no significant difference in either the PFBV or PFCV between the Chiari and control groups. 


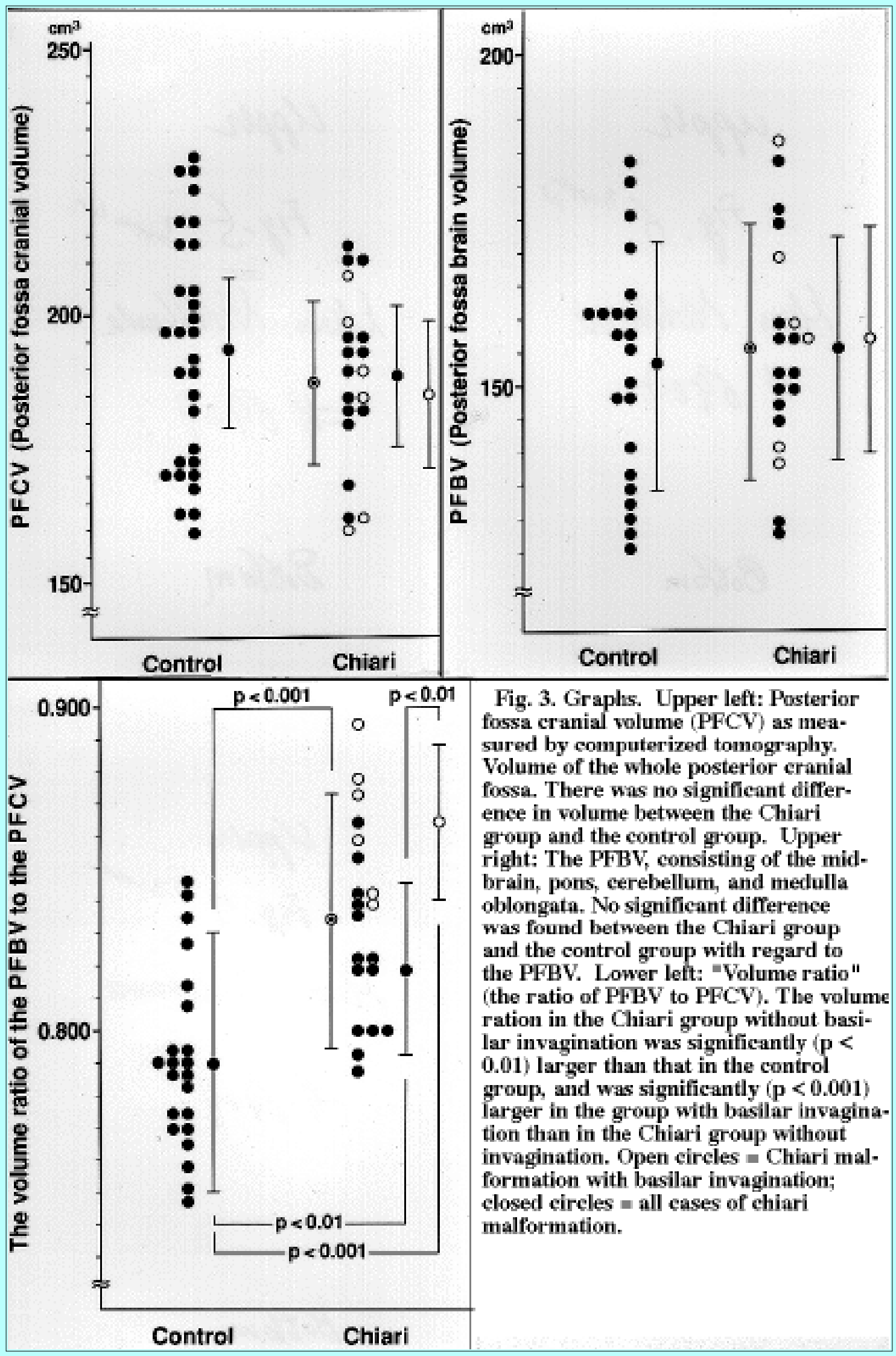

\section{Overcrowding of the Posterior Cranial Fossa}

A significant difference $(\mathrm{p}<0.001)$ was found, however, in the volume ratio of the PFBV to the PFCV (Fig. 3 lower left). The mean volume ratio was 0.833 in the Chiari group ( 0.813 in patients without vs. 0.863 in those with basilar invagination) and 0.790 in the control group. The volume ratio in the Chiari 
group without basilar invagination was significantly $(\mathrm{p}<0.01)$ larger than in the control group, and the volume ratio in the group with basilar invagination was even significantly $(\mathrm{p}<0.01)$ larger than the ratio in the Chiari group without invagination.

\section{Morphometric Study Using MR imaging}

Compared to the control group, regardless of basilar invagination there was a significant difference ( $\mathrm{p}<$ 0.001 ) in the mean angle of the cerebellar tentorium against Twining's line, which was 44.6š in the Chiari group (44̌̌ in patients without vs. 44.9š in those with basilar invagination) and 36.2 ̌s in the control group (Fig. 4). This indicated that the cerebellar tentorium was significantly steeper in the Chiari group than in the control group.

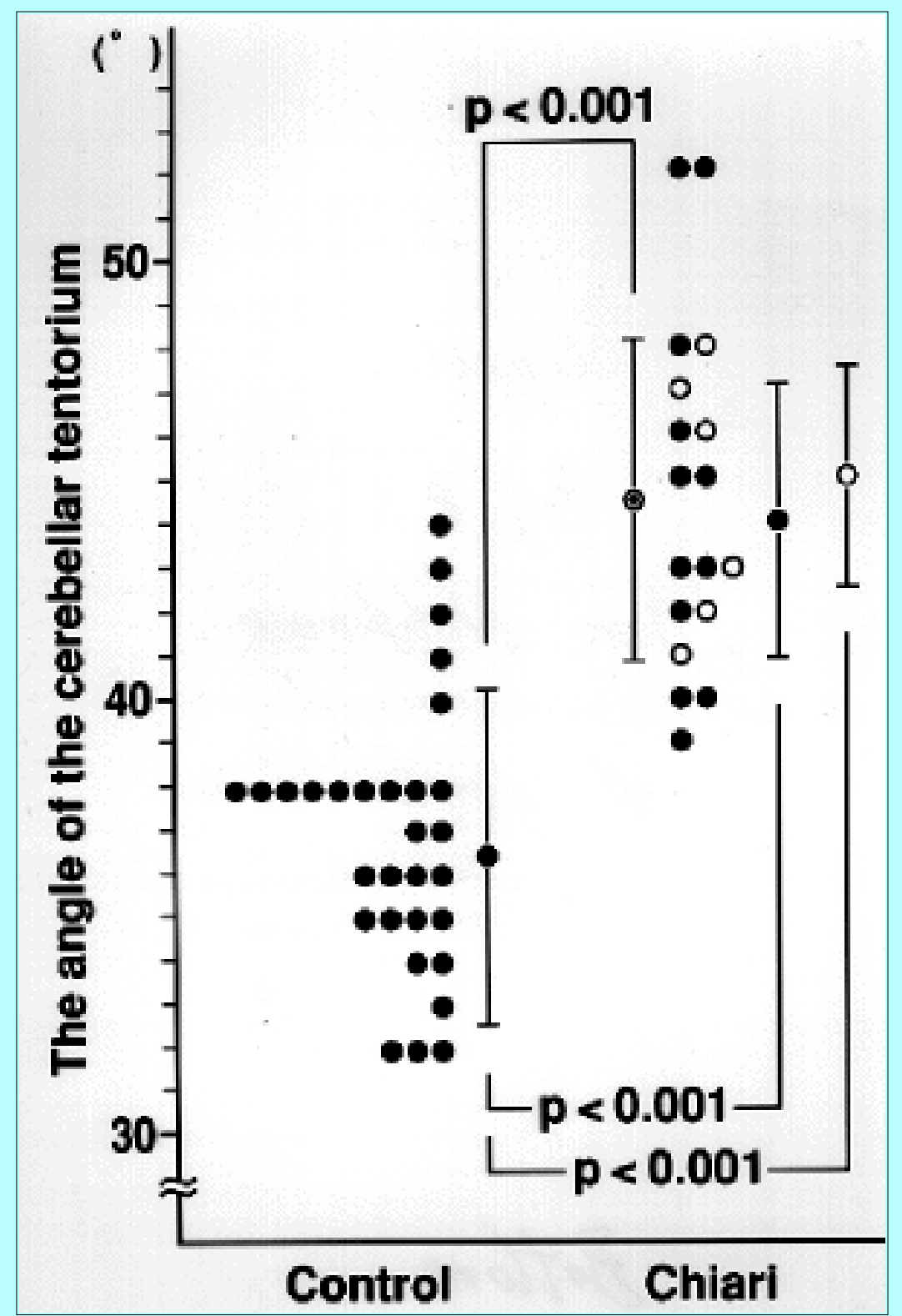

Fig. 4. Chart showing the angle of the cerebellar tentorium to Twining's line. The angle in patients with adult-type Chiari malformation was significantly $(\mathrm{p}<0.001)$ larger than that in the control subjects, irrespective of basilar invagination. Open circles $=$ Chiari malformation with basilar invagination; closed circles $=$ all cases of Chiari malformation .

The relationship between the volume ratio and the steepness of the tentorium was significant $(\mathrm{y}=121 \mathrm{x}$ - 
58.3, $\mathrm{p}<0.01$ ) in all the individuals studied (Fig. 5). No significant relationship was found, however, between the volume of the herniated brain below the foramen magnum (range 1.2-3.8 cubic centimeters, mean 2.2 cubic centimeters \pm standard deviation 0.8 cubic centimeters) and the PFCV or between the volume of the herniated brain below the foramen magnum and the volume ratio.

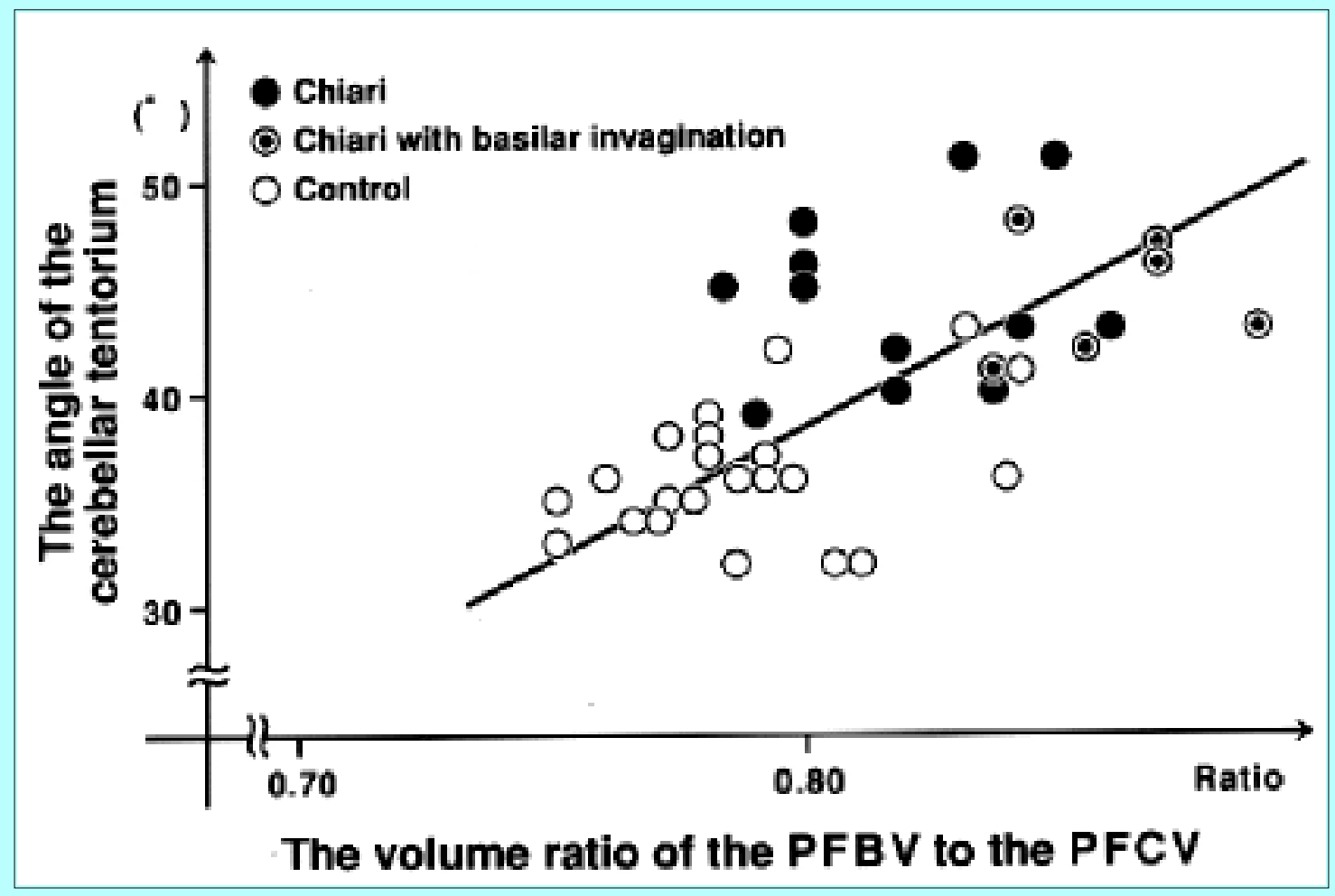

Fig. 5. Graph displaying the relationship between the posterior fossa volume ratio (PFBV/PFCV) and the angle of the tentorium. When the posterior fossa volume ratio is correlated with the angle of the tentorium, the slope of the line is significant $(p<0.01)$.

The sphenooccipital synchondrosis was clearly visible in 14 of 20 patients with adult-type Chiari malformation and in 25 of 44 normal control subjects who underwent MR imaging, although it was not demonstrated by x-ray tomography (Table 1). Of the individuals with a clearly visualized sphenooccipital synchondrosis, the top of the dorsum sellae, which was defined as the top of the clivus, was clearly demonstrated in the MR images of 10 patients in the Chiari group and 10 in the control group. Although there was no significant difference in the length of the basisphenoidal or basioccipital part of the clivus between the Chiari and control groups, patients with basilar invagination had a significantly $(\mathrm{p}<0.01)$ shorter basiocciput than the control group. The mean length of the basisphenoidal part in the Chiari group was $18.5 \mathrm{~mm}$ versus $20.6 \mathrm{~mm}$ in the control group; the mean length of the basioccipital portion in the Chiari group was $24.4 \mathrm{~mm}$ versus $28.1 \mathrm{~mm}$ in the control group and was even shorter in patients with basilar invagination at $20.8 \mathrm{~mm}$ (Fig. 6). 


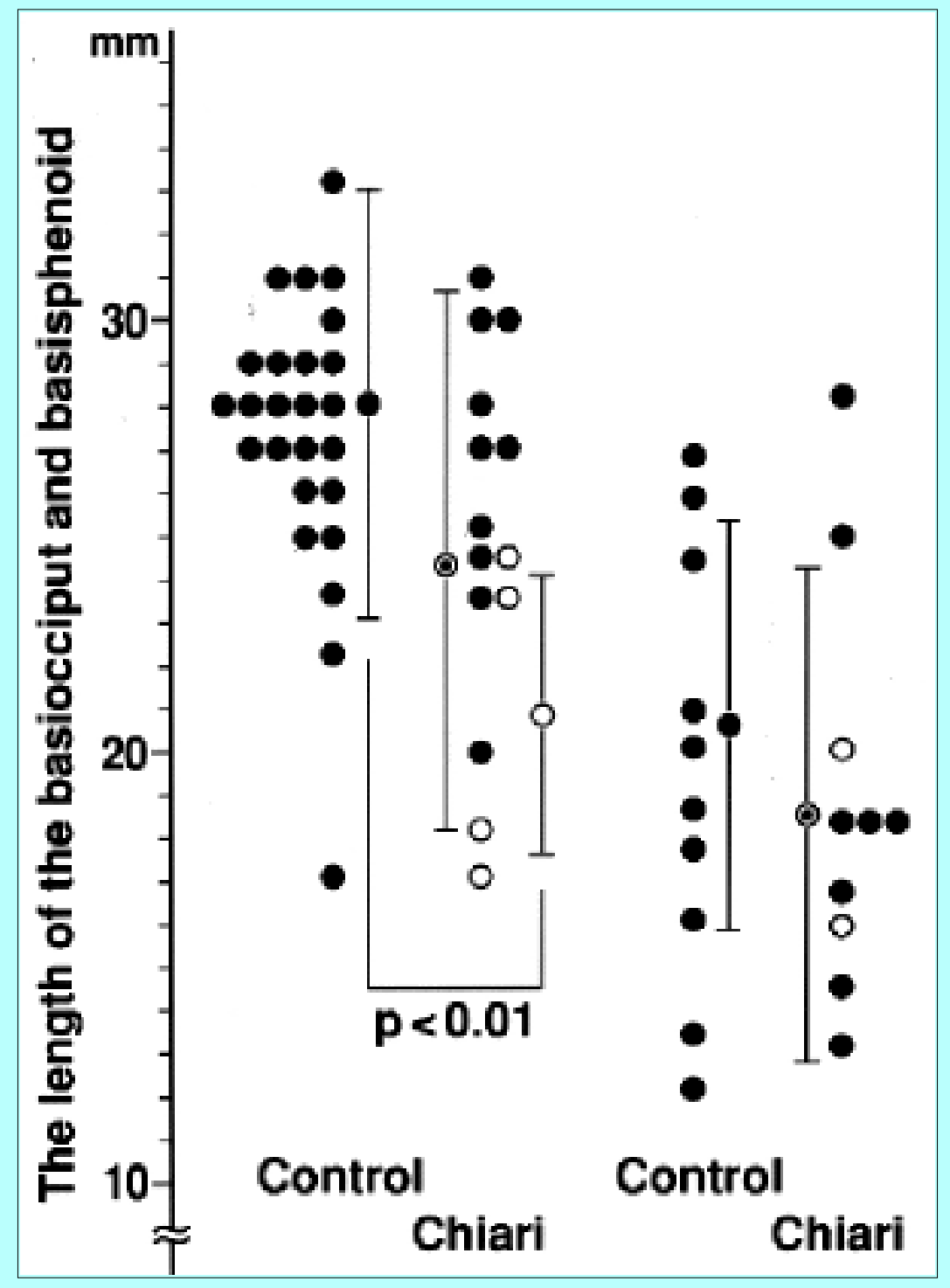

Fig. 6. Graph showing the lengths of the basisphenoid and basiocciput. No significant difference was found in the length of the basisphenoid or basiocciput between the Chiari group and the control group, but patients with basilar invagination had a significantly $(\mathrm{p}<$ 0.01) shorter basiocciput than control subjects. Open circles $=$ Chiari malformation with basilar invagination; closed circles $=$ all cases of Chiari malformation .

Comparing the Chiari group to the control group, no significant difference was found in the length of the brainstem from the midbrain-pons junction to the medullocervical junction $(50.2 \mathrm{~mm}$ in the Chiari group and $49 \mathrm{~mm}$ in the control group) or in the long axial length of the cerebellar hemisphere $(49.1 \mathrm{~mm}$ in the Chiari group and $47.7 \mathrm{~mm}$ in the control group) (Fig. 7), and no significant difference in these lengths was found between the patients with and without basilar invagination. In the 20 patients with adult-type Chiari malformation studied by MR imaging, eight displayed downward herniation of the medulla oblongata below the foramen magnum. Of these eight patients, six had accompanying basilar invagination and the remaining two displayed a very short clivus (46 $\mathrm{mm}$ and $47.3 \mathrm{~mm}$ ) (Fig. 2 upper left). 


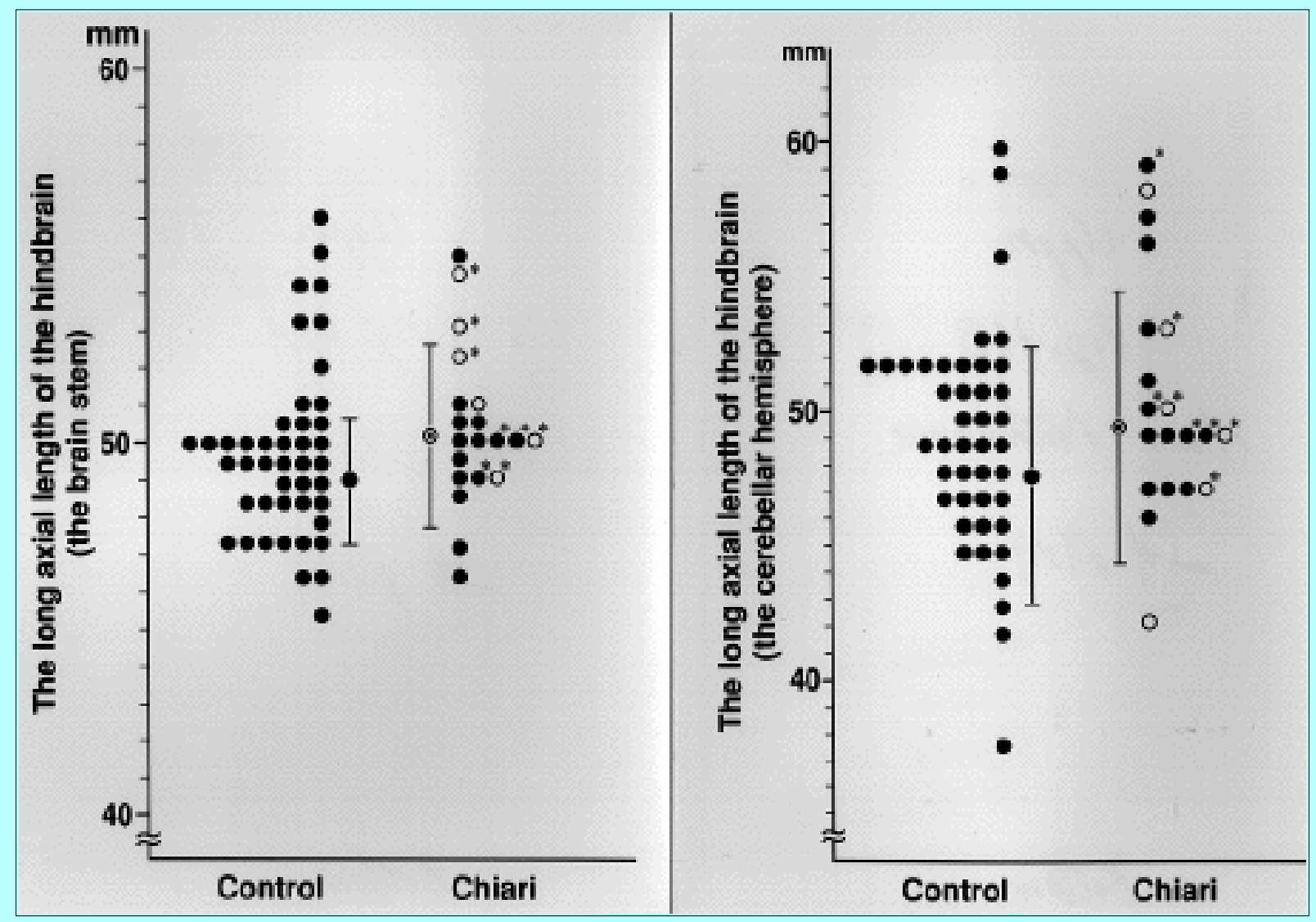

Fig. 7. Graphs showing axial lengths of the hindbrain. Left: Axial length of the brainstem between the midbrain-pons junction and the medullocervical junction. Right: Axial length of the cerebellar hemisphere. There was no significant difference in the axial length of the hindbrain between the Chiari group and the control group, irrespective of basilar invagination. Open circles $=$ Chiari malformation with basilar invagination; closed circles $=$ all cases of Chiari malformation. *Patients with downward herniation of the medulla oblongata below the foramen magnum in addition to tonsillar herniation.

\section{DISCUSSION}

\section{Overcrowding of the Posterior Cranial Fossa}

To estimate overcrowding in the posterior cranial fossa of patients with adult-type Chiari malformation, we used the volume ratio of the PFBV to the PFCV. This ratio in the Chiari group, associated basilar invagination notwithstanding, turned out to be significantly larger than in the control group (Fig. 3 lower left). This result was obtained even though there was no significant difference in the PFCVs, encompassed by both the bony and tentorial structures (Fig. 3 upper left) or in the PFBVs, consisting of the midbrain, pons, cerebellum, and medulla oblongata (Fig. 3 upper right). In a previous report we looked at the distance from the basilar artery to the posterior aspect of the clivus at the midportion of the clivus on vertebral angiograms in adult-type Chiari malformation; we found significant encroachment of the basilar artery with respect to the clivus as an indirect sign of overcrowding in the posterior cranial fossa.[22] The present study clearly showed overcrowding of the posterior cranial fossa in adult-type Chiari malformation by direct measurement of the volume of the posterior cranial fossa and the volume of the neural structures contained within it.

Three recent morphometric studies have suggested a significantly smaller volume in the lower half, or bony portions, of the posterior cranial fossa in adult patients with Chiari malformation.[23,25,28] 
However, the authors failed to consider the upper half, or tentorial part, of the posterior fossa and ignored the size of the neural structures contained in the posterior cranial fossa. $[23,25,28]$ To estimate overcrowding properly, we decided that it was necessary to use the volume ratio of the PFBV to the PFCV (Fig. 3).

Patients with adult-type Chiari malformation were strictly selected through surgical exploration of the major cistern in addition to neuroimaging because various pathological conditions, such as hydrocephalus, arachnoiditis at the major cistern, spinal shunt for hydrocephalus, and others, which could induce secondary tonsillar herniation, might have misled the results of the morphometric study.[29]

\section{Associated Occipital Hypoplasia}

The present study showed that patients with adult-type Chiari malformation had various degrees of occipital hypoplasia and structured abnormalities of the tentorium, but displayed no significant abnormalities of the neural structures (that is, the hindbrain) in the posterior cranial fossa. In the Chiari group (with and without basilar invagination), two embryogenic parts of the occipital bone (the exocciput and supraocciput) were significantly shorter than in the control group (Fig. 2 upper right and lower left), although no significant difference was revealed in the long axial lengths of the hindbrain (the pons, medulla oblongata, and cerebellum) (Fig. 7). The present study also showed that the cerebellar tentorium in the Chiari group was significantly steeper than in the control group, even though no significant difference in the total PFCV was found (Fig. 4).

When the more prominent structural abnormalities in the occipital enchondrium are considered in conjunction with the less significant structural abnormalities in the hindbrain in the posterior cranial fossa, the overcrowding observed in adult-type Chiari malformation can be regarded as the primary cause of downward herniation of the normally developing caudal hindbrain.[6] Overcrowding in the posterior cranial fossa may induce a consistent upward shifting of its contents, leading to a significantly steeper tentorium as well as a downward shifting of the hindbrain. The volume of the herniated brain below the foramen magnum displayed no relationship to the volume of the posterior cranial fossa and the volume ratio of the PFBV to the PFCV. The volume of the herniated brain below the foramen magnum was quite small (lt 2\%) compared to the volume of the tentorial parts of the posterior cranial fossa, and thus was only minimally related to overcrowding. The volume ratio and the angle of the tentorium showed a significant correlation (Fig. 5), indicating that the volume of the tentorial parts of the posterior cranial fossa may relieve overcrowding of the posterior cranial fossa. The upward shifting of the cerebellar tentorium may explain why the PFCV was not significantly smaller in the Chiari group. It can be inferred that overcrowding of the posterior cranial fossa induces remodeling of neural structures as the cerebellar tentorium shifts upward and the cerebellar tonsils herniate to accommodate the growing brain, rather than remodeling the cranium.

When we looked into the incidence of basilar invagination and downward herniation of the medulla oblongata in patients with adult-type Chiari malformation, we found that of eight patients with medullary herniation in addition to tonsillar herniation, six had basilar invagination and the remaining two had a very short clivus (Fig. 2 upper left). Of the six patients with basilar invagination, four in whom the sphenooccipital synchondrosis was identified on MR imaging had a significantly short basiocciput (Fig. 6). On the other hand, the eight patients with medullary herniation showed no significant difference in their hindbrain structures from the normal control subjects. Looking at the upper part of the clivus 
composed of the sphenoidal bone, no significant difference was found among the patient group, the patient group with basilar invagination, and the control group. Thus, the downward herniation of the medulla oblongata observed in adult-type Chiari malformation with basilar invagination can be explained by shortening of the basiocciput rather than by a primary neural abnormality associated with Chiari malformation, in addition to overcrowding in the posterior cranial fossa due to occipital hypoplasia.[24]

\section{Embryological Aspects of the Base of the Skull in Adult-Type Chiari Malformation}

The present study took into consideration the embryological development of the human occipital enchondrium, and each part of the base of the skull in patients with adult-type Chiari malformation was compared to that of normal controls using available neuroradiological techniques. Although the results obtained were for only a limited number of individuals in the patient and control groups, it was found that two parts of the occipital enchondrium (the exocciput and supraocciput) were underdeveloped in patients with adult-type Chiari malformation, and that all three parts of the occipital enchondrium (the exocciput, supraocciput, and basiocciput) were underdeveloped in patients with basilar invagination (Figs. 2 and 6). No significant difference was found in the length of the basisphenoid of the sphenoidal bone between the Chiari group and the control group. O'Rahilly and colleagues[20] have proved that the basioccipital and exoccipital portions of the occipital bone up to the top of the jugular tubercle are derived from the occipital somites in the human fetus. The results of the present morphometric study strongly imply normal development of the hindbrain and underdevelopment of the occipital somites in patients with adult-type Chiari malformation.

Marin-Padilla and Marin-Padilla[16,17] suggested a hypothesis of cephalic axial skeletal neural dysraphic disorder to explain the brain abnormalities associated with pediatric-type Chiari malformation and postulated that paraxial mesodermal insufficiency contributed to a cephalic axial skeletal neural dysraphic disorders as anencephaly, a dysraphic anomaly, or even Chiari malformation. According to this hypothesis, paraxial mesodermal insufficiency or primary lesion of the somitic structures may induce various neural abnormalities in pediatric-type Chiari malformation. Thus, when paraxial mesodermal insufficiency is regarded as the pathogenesis of Chiari malformation, adult-type Chiari malformation can be considered a mild form and the pediatric type a severe form.

\section{Surgical Treatment of Syringomyelia Associated With Adult-Type Chiari Malformation}

The syringomyelia quite often associated with adult-type Chiari malformation is now treatable by different types of surgical intervention, such as drainage of cerebrospinal fluid (CSF) or decompression of the foramen magnum with or without plugging the central canal.[3,10,14,15,26] Recent flow studies of CSF by MR imaging have shown that blockage of CSF flow at the foramen magnum between the intracranial and intraspinal subarachnoid space is the most important factor exacerbating syringomyelia associated with adult-type Chiari malformation.[1,7,10,19,30] Overcrowding in the posterior cranial fossa, in addition to downward herniation of the caudal portion of the hindbrain, can induce such a CSF blockage at the foramen magnum. We believe that the most suitable treatment for syringomyelia associated with adult-type Chiari malformation is not to drain the fluid in the syrinx, but to improve CSF flow around the foramen magnum by expansion of the abnormally small space surrounded by the underdeveloped occipital bone.[11,12,22,27]

\section{CONCLUSIONS}

Our results lead us to the conclusion that adult-type Chiari malformation is most likely produced 
primarily by underdevelopment of the occipital enchondrium, possibly due to underdevelopment of the occipital somite originating from the paraxial mesoderm. Overcrowding in the posterior cranial fossa due to a normal-sized hindbrain in the underdeveloped occipital enchondrium secondarily induces a downward herniation of the brain as well as an upward shift of the cerebellar tentorium. Associated basilar invagination due to a more severely underdeveloped occipital enchondrium further exacerbates overcrowding of the posterior cranial fossa.

\section{Acknowledgment}

We thank Miguel Marin-Padilla, M.D., for his excellent suggestions in the preparation of this manuscript.

\section{References}

1. Ball MJ, Dayan AD: Pathogenesis of syringomyelia. Lancet 2:799-801, 1972

2. Barry A, Patten BM, Stewart BH: Possible factors in the development of the Arnold-Chiari malformation. J Neurosurg 14:285-301, 1957

3. Batzdorf U: Chiari I malformation with syringomyelia. Evaluation of surgical therapy by magnetic resonance imaging. J Neurosurg 68:726-730, 1988

4. Bindal AK, Dunsker SB, Tew JM Jr: Chiari I malformation: classification and management. Neurosurgery 37:1069-1074, 1995

5. Chiari H: Concerning alterations in the cerebellum resulting from cerebral hydrocephalus. Pediatr Neurosci 13:3-8, 1987

6. Dobbing J, Sands J: Quantitative growth and development of human brain. Arch Dis Child 48:757-767, 1973

7. Du Boulay G, Shah SH, Currie JC, et al: The mechanism of hydromyelia in Chiari type 1 malformations. Br J Radiol 47:579-587, 1974

8. Dyste GN, Menezes AH, VanGilder JC: Symptomatic Chiari malformations. An analysis of presentation, management, and long-term outcome. J Neurosurg 71:159-168, 1989

9. Friede RL, Roessmann U: Chronic tonsillar herniation. An attempt at classifying chronic herniations at the foramen magnum. Acta Neuropathol 34:219-235, 1976

10. Gardner WJ, Goodall RJ: The surgical treatment of Arnold-Chiari malformation in adults. An explanation of its mechanism and importance of encephalography in diagnosis. J Neurosurg 7:199-206, 1950

11. Hakuba A: [Surgical treatment of syringomyelia associated with Chiari malformation.] Spinal Surg 4:69-76, 1990 (Jpn)

12. Hakuba A: Syringomyelia, in Kikuchi H, Hakuba A (eds): Illustrated Techniques in Microneurosurgery. Tokyo: Igaku-shoin, 1990, pp 249-256 
13. Ho PSP, Yu SW, Czervionke LF, et al: MR appearance of gray and white matter at the cervicomedullary region. AJNR 10:1051-1055, 1989

14. Levy WJ, Mason L, Hahn JF: Chiari malformation presenting in adults: a surgical experience in 127 cases. Neurosurgery 12:377-390, 1983

15. Logue V, Edwards MR: Syringomyelia and its surgical treatment--an analysis of 75 patients. $\mathbf{J}$ Neurol Neurosurg Psychiatry 44:273-284, 1981

16. Marin-Padilla M: Notochordal-basichondrocranium relationships: abnormalities in experimental axial skeletal (dysraphic) disorders. J Embryol Exp Morphol 53:15-38, 1979

17. Marin-Padilla M, Marin-Padilla TM: Morphogenesis of experimentally induced Arnold-Chiari malformation. J Neurol Sci 50:29-55, 1981

18. McLone DG, Knepper PA: The cause of Chiari II malformation: a unified theory. Pediatr Neurosci 15:1-12, 1989

19. Oldfield EH, Muraszko K, Shawker TH, et al: Pathophysiology of syringomyelia associated with Chiari I malformation of the cerebellar tonsils. Implications for diagnosis and treatment. J Neurosurg 80:3-15, 1994

20. O'Rahilly R, Müller F, Meyer DB: The human vertebral column at the end of the embryonic period proper. The occipitocervical region. J Anat 136:181-195, 1983

21. Paul KS, Lye RH, Strang FA, et al: Arnold-Chiari malformation. Review of 71 cases. J Neurosurg 58:183-187, 1983

22. Sakamoto H, Nishikawa M, Nakanishi N, et al: [Surgical treatment of syringomyelia associated with Chiari malformation.] Spinal Surg 8:1-6, 1994 (Jpn)

23. Schady W, Metcalfe RA, Butler P: The incidence of craniocervical bony anomalies in the adult Chiari malformation. J Neurol Sci 82:193-203, 1987

24. Schmidt H, Sartor K, Heckl RW: Bone malformations of the craniocervical region, in Vinken PJ, Bruyn GW (eds): Handbook of Clinical Neurology. Vol 32: Congenital Malformations of the Spine and Spinal Cord. Amsterdam: Elsevier/North-Holland, 1978, pp 1-98

25. Stovner LJ, Bergan U, Nilsen G, et al: Posterior cranial fossa dimensions in the Chiari I malformation: relation to pathogenesis and clinical presentation. Neuroradiology 35:113-118, 1993

26. Tator CH, Meguro K, Rowed DW: Favorable results with syringosubarachnoid shunts for treatment of syringomyelia. J Neurosurg 56:517-523, 1982

27. Tokuno H, Hakuba A, Suzuki T, et al: Operative treatment of Chiari malformation with syringomyelia. Acta Neurochir Suppl 43:22-25, 1988

28. Vega A, Quintana F, Berciano J: Basichondrocranium anomalies in adult Chiari type I malformation: a morphometric study. J Neurol Sci 99:137-145, 1990

29. Welch K, Shillito J, Strand R, et al: Chiari I "malformation"--an acquired disorder? J Neurosurg 55:604-609, 1981 
30. Williams B: A critical appraisal of posterior fossa surgery for communicating syringomyelia. Brain 101:223-250, 1978

Manuscript received April 5, 1996.

Accepted in final form August 21, 1996.

This study was supported by Research Grant 5B-3 for nervous and mental disorders from Japan's Ministry of Health and Welfare.

Address reprint requests to: Misao Nishikawa, M.D., Department of Neurosurgery, Osaka City General Hospital, 2-13-22 Miyakojima-hondori, Miyakojima-ku, Osaka 534, Japan. 